\title{
Between Survey and Communication. On Distance Experiences
}

\author{
Federica Maietti \\ Andrea Zattini
}

Abstract

The paper presents the results of a research and educational process, developed during the period in which the pandemic situation required to overcome distances by experimenting with new educational and applicative approaches in the field of surveying and representation. The aim of the process is to define an approach to the survey of architecture and its graphic communication, using different representative techniques, not as a simple adaptation to contingencies but as an opportunity for in-depth study and exploration of new possible horizons.

The results, synthetically outlined in this contribution, show the multiple analytical possibilities, through drawing, starting from indirect experiments, based on documentary sources, and specific experiences of direct and integrated instrumental survey. The main objective of transmitting the role of architectural representation as a tool for analysis and as a means of visual communication has led to elaborations in which the management of digital images through three-dimensional models and two-dimensional representations is combined with critical-interpretative graphic syntheses. In this kind of drawings, the most effective communication strategies are identified, in line with the main features of the architectures analysed.

Keywords

drawing, representation, communication, survey, education.

Examples of critical-interpretative graphic syntheses of renowned architectures assigned to be modelled in parametric environment and through photorealistic renderings.
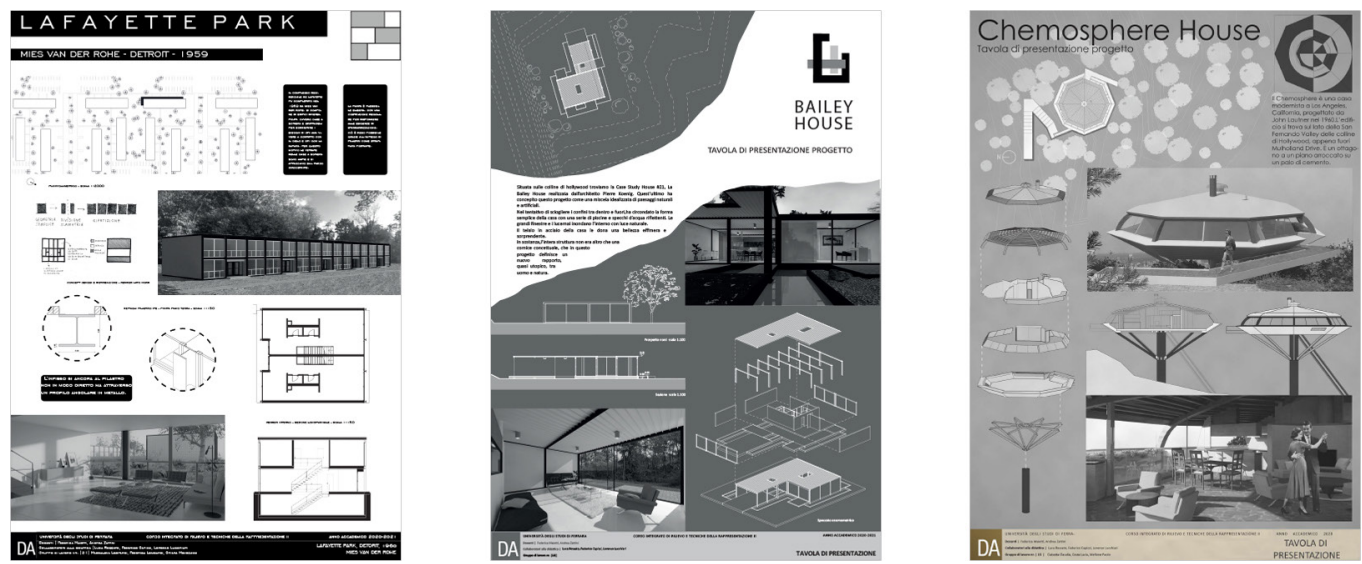


\section{Introduction}

The pandemic condition that has been affecting our lives in many ways over the past year has not only provided an opportunity to reinvent teaching processes and procedures in new ways imposed by 'distance', but also a time to reconsider the meaning of transmitting knowledge through new and unexplored methodologies.

The impact of the pandemic emergency has involved different domains of the scientific disciplinary field of Drawing, stimulating, for instance, a wide discussion, at national and international level, on the digitisation of cultural heritage and on new forms of fruition [Lo Turco 2020].This debate includes an increasing use of digital technologies to gain immersive experiences, but also to access new levels of knowledge remotely accessible [Clini 2020]. Accessibility has been, and is, one of the keywords throughout this period. The analysis of new digital approaches to explore places while being isolated has led to a new exploration and deepening of the possible meanings of the virtual.

However, one of the most crucial impacts has certainly concerned, and is still concerning, the world of education, school, university, the possibility of carrying on transmitting knowledge and interest in learning, at different educational levels, despite distances and through the digital, a topic already at the centre of disciplinary scientific debate regardless of contingencies [Luigini 20l7].

In the specific disciplinary field of Drawing at the level of university teaching and research, this impact has gone beyond the boundaries of merely organisational logistics. The condition has led to a reorganisation aimed at making the most of resources that are not only 'media' or interfaces - including digital devices and the new technologies that allow coexistence in virtual rooms - but also, and above all, communicative resources. In this sense, the teaching of the disciplines of representation as a knowledge, expressive and analytical tool has been a significant test bed. How to 'evolve' to face the contingencies, exploiting digital technology to transmit content and knowledge? How to replace the crucial time of discussion, pencil in hand, when assessing and revising the graphic works produced by the students?

These questions can only be partially resolved with the transmission of data and content through the digital 'medium'. The road taken has attempted to bring together research and educational experimentation, finding new meanings, reconnecting analogue and digital, and proposing new educational approaches between surveying, modelling and visuality [Fatta 2020].

\section{Topics and educational methodologies}

The field of application that has allowed dealing with a new educational approach is the Integrated Course of Surveying II and Techniques of Representation.

In addition to the acquisition of theoretical and procedural knowledge related to the indirect instrumental architectural survey, together with the application of traditional and documental direct methodologies [Bertocci 20 I2], the course deals with the topics of the three-dimensional digital representation of the architecture. This topic is aimed at the critical assessment of an architectural work, realizing a three-dimensional model and the related drawings in orthogonal projection, connected to the interpretative [Bianchini 20I4] and logical-descriptive path.

At the start of the activities, the opportunity to carry out a direct survey experience, aimed at architectural and thematic survey, and analytical photo straightening, allowed the students to survey onsite (an experience that had inevitably been lacking in the previous semester). The following lockdown required the activities to be redirected, so that they could be carried out remotely, leading to a focus on "indirect survey" procedures of renowned existing architectures through documentary sources, aimed at the creation of knowledge graphic materials (through sketches and vector graphics), geometrically coherent, for the creation of the digital model.

The thematic framework chosen to select the architectures to be assigned to the students is twentieth-century architecture in the United States, thus continuing a line of research 
Fig. I. Architectura drawings extracted from

USAFA Cadet Chapel by

Walter Netsch, Colorado

Walter Nets
$1959-1962$.
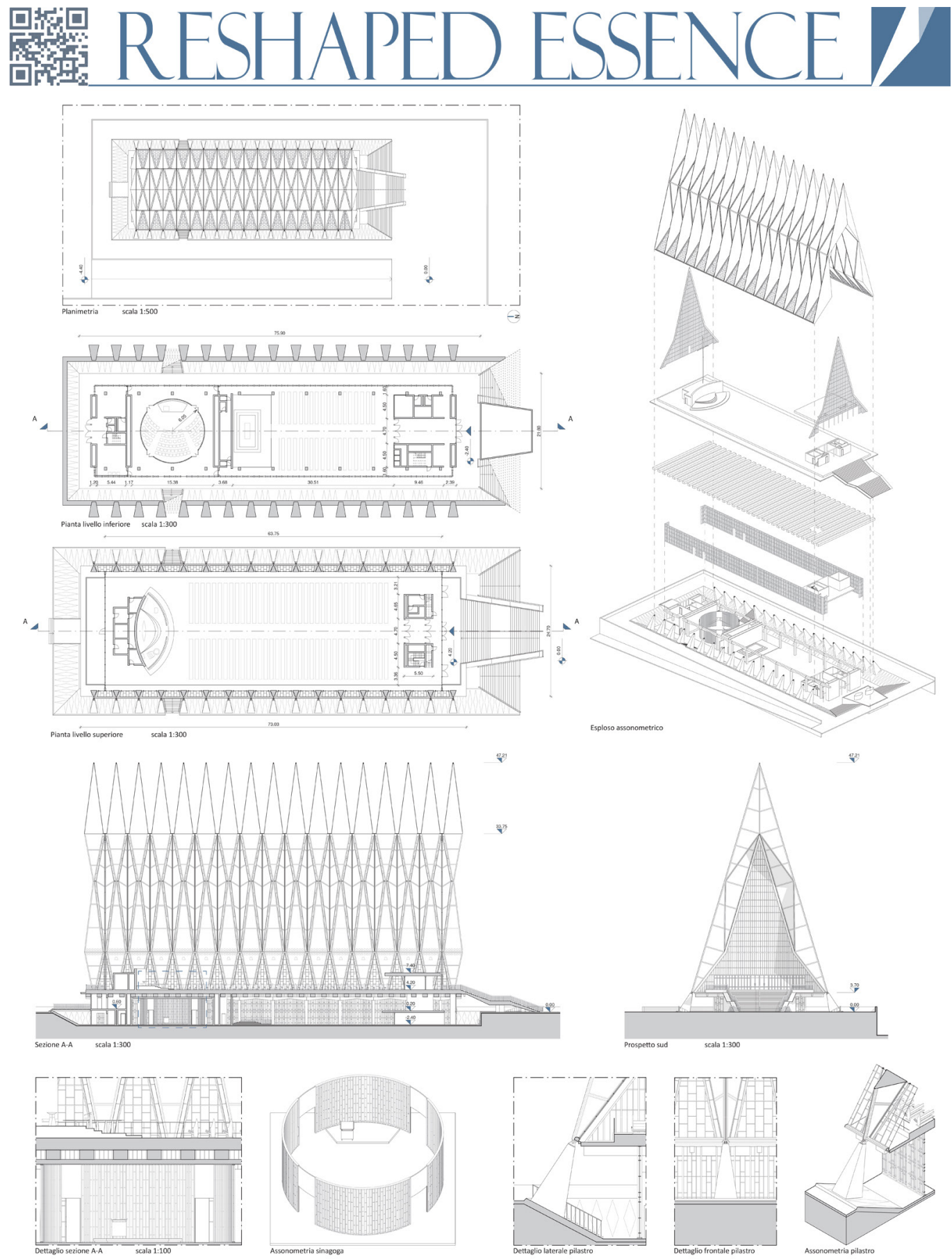
that of Modernism [Rossato 2020], previously experimented through applications in Latin America and India [ $\mathrm{I}]$.

To the students were therefore assigned architectures by Frank LloydWright [Frampton 1993], Ludwig Mies van der Rohe, Albert Frey, Philip Johnson, Charles Eames, Eero Saarinen, Pierre Koenig and others, stimulating them to carry out extensive preliminary research using different sources, analysing graphics, bibliographies and documents [Zevi 2004; Benevolo 2010].

This process provided the basis for the parametric modelling of the assigned projects, allowing students to finalise the representative experience on the architectures, more or less complex, modelling them entirety (fig. I), through a knowledge process that goes from documentation to analysis to representation, up to rendering to simulate the environmental, material and conservation features of the architectures analysed.

At the same time, the field of integrated techniques for indirect architectural surveying was addressed, proposing the development of onsite trainings organised to be carried out in safety and to encourage collaboration and interoperability between the students groups, which, although working remotely, were expected to compare and integrate the digital data collected on contiguous areas.

\section{Digital data retrieving: an interactive process}

From the point of view of the educational 'experimentation' to be managed, the greatest impact concerned the impossibility of living the experience of direct survey as an operational opportunity for in-depth application [Docci $20 \mathrm{l} \mathrm{I}$ ] but also as a collective experience of comparison, integration and exchange onsite.

In the framework of the course, the adaptation to the new conditions, despite the beginning of the education experience that provided a short window of opportunity for face-to-face work, has been a matter of reflection. These considerations led to a natural evolution of the educational content and of the ways of involving students, offering new perspectives that have overcome the initial difficulties.

The experience of direct and thematic survey and the applications of analytical photo straightening brought the students closer to the fundamentals of digital photogrammetry, which formed an integrating part of the survey experience that the students were required to carry out.

The pandemic situation, however, allowed the students to carry out targeted direct survey experiences [Albisinni 20I4], although mostly on their own or in very small groups, focusing the fieldwork on the application of tools that the students could manage autonomously. The experience of applying digital photogrammetry has been proposed on contexts accessible without particular difficulties from the point of view of locations, dimensions and complexity of the decorative elements. These areas were located in the historical centre of Ferrara and Bologna; portions of porticos have been chosen, which allowed the development of the photo modelling experience [De Luca 20l I] by integrating the external façade with the internal surfaces, in particular the vaulted ones. The direct survey of the same areas and the representation by means of sketches made it possible to strengthen the analytical-representative experience through the indispensable use of hand drawing. Moreover, the direct survey of a set spatial coordinates was integrated to the digital model, in order to check the outcomes from the Structure from Motions procedure, verify the error and propose critical considerations on the accuracy of the applied methodology. This phase was essential during the processing of digital data acquired on contiguous areas, for which the students were asked to integrate the individual models into a single overall model.

In addition to the realistically textured three-dimensional representations, further processing of the dense point cloud was required in order to parametrically model the same areas surveyed, by means of rectified geometries or hyper-modelling depending on the complexity of the architectural elements, by stimulating to interpret or understand the architectural shapes. 


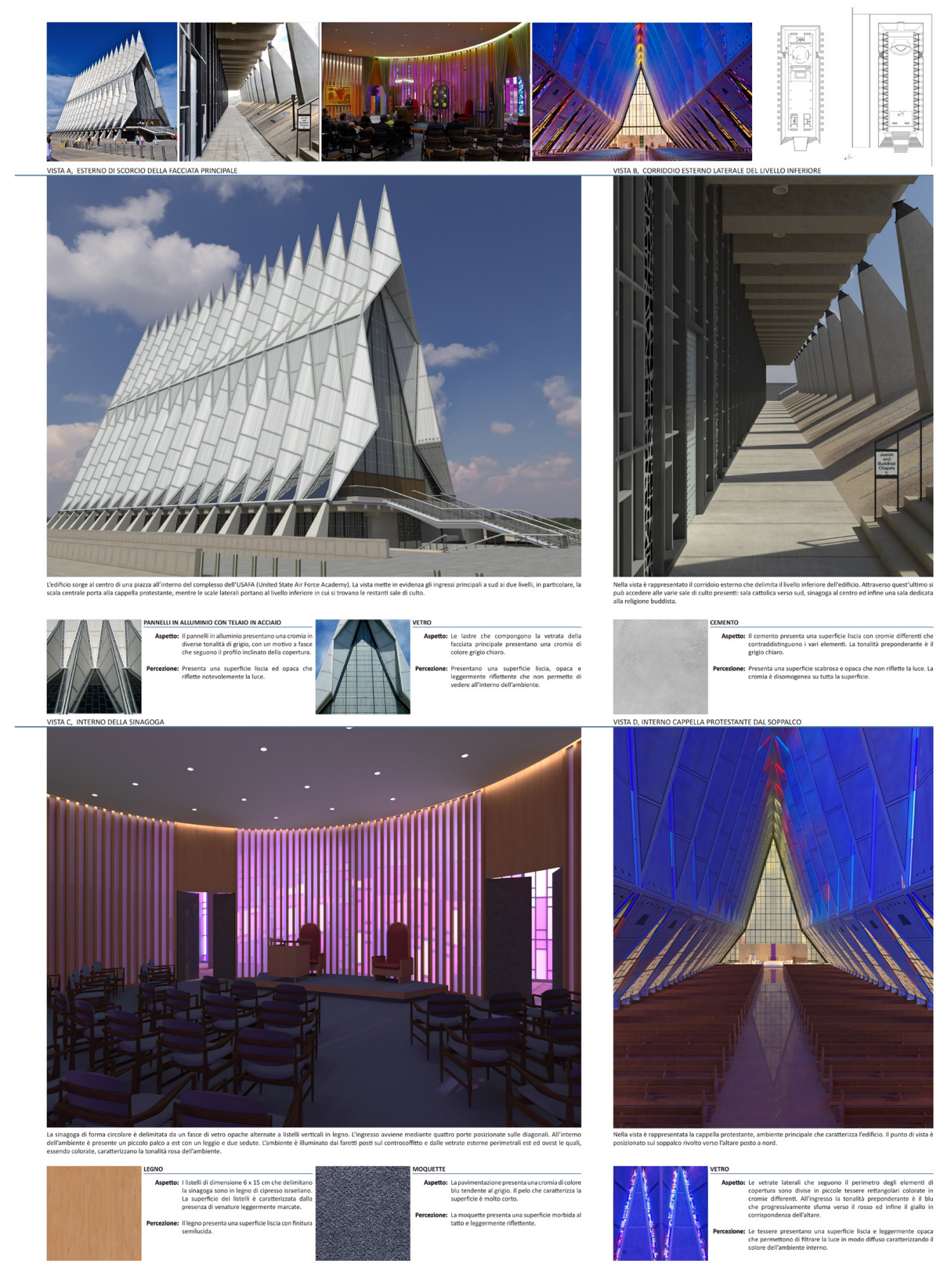




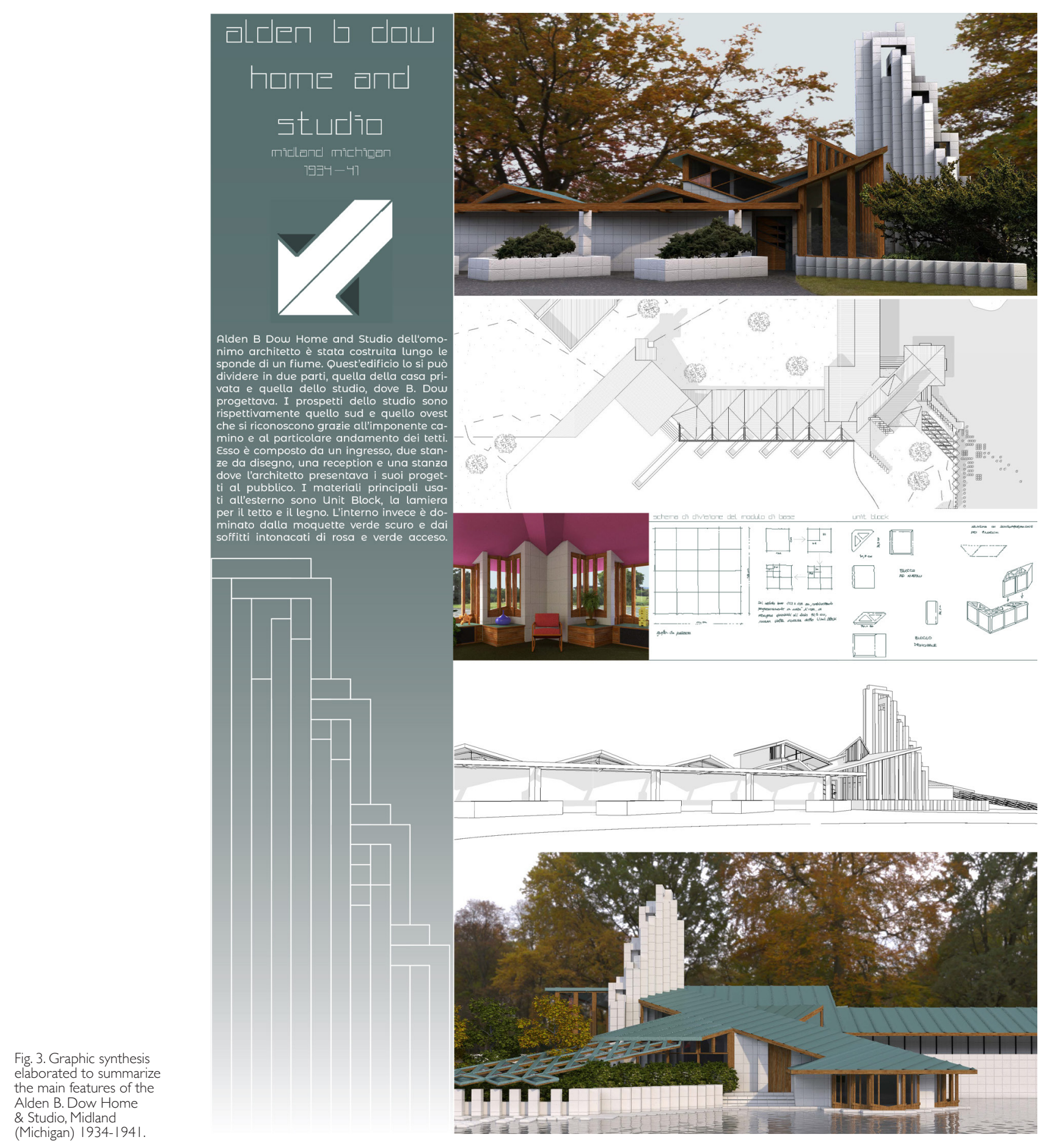




\section{Representation and communication}

From a representative point of view, the elaborations required for the architectures assigned as an indirect survey exercise using documentary sources included the three-dimensional model developed in a BIM (Building Information Modeling) environment and the related orthogonal projection drawings, as well as photorealistic renderings (fig. 2) [Brusaporci 2019]. In this process the documentation phase is central, not only from a graphic and photographic point of view, that is, in tracing all the sources that would allow the metric, dimensional, compositional, material, etc. data to be organised on sketches, but also from a historical and cultural point of view.

This analytical approach had to find coherence in the representations of the assigned architecture, from the graphic point of view and the communication of the drawings and exposition of the contents according to a critical approach. To this end, a virtual workshop of dynamic graphic layout was proposed, carried out through specific sessions of in-depth study over the course of the semester, assigning as a first phase the task of searching for examples of graphic works considered interesting in terms of the communication of a project.The students were asked to write a short critical essay on the chosen work, highlighting its strengths and weaknesses, or simply the reasons for their choice. They were then asked to arrange a similar graphic layout taking into account the previous assessment, integrating, eliminating or rearranging the contents of the graphic panel.

Finally, on the basis of this process, the students were asked to draw up a graphic synthesis or overview of the architecture assigned at the beginning of the course. This synthesis had to be carried out by choosing the most effective communication strategy (figs. 3, 4), which would highlight the main features of Modernist architecture, the intentions of the designer, the implicit cultural aspects, and the personal, critical-interpretative understanding, through a coherent representation, in which graphic and textual language coexisted.

\section{Conclusions}

The results of the work briefly presented move from the continuous search for educational tools increasingly focused on the transmission of all the skills required to young professionals by the contemporary world, in terms of digital tools and of the critical-interpretive skills that put the drawing at the heart of a continuous research. In fact, contemporaneity reveals not only the growing demand for digital graphic-representational skills, but also the need to link this rapid progress of technological innovations with an increasingly necessary critical, interpretative and sensitive approach to the relationship of necessity between survey and representation, between drawing and design, between knowledge and visual communication.

The particular conditions in which the presented experiences were carried out provided the motivation to deepen, and to convey, this relationship of necessity, proposing activities in which the students could work in an integrated way even if at a distance, stimulating individual work while working in groups, and encouraging comparison, collaboration and discussion.

The limited opportunities for co-participation in onsite activities led to the proposal of short experiences in which the procedural and methodological comparison and the cross integration of the data acquired could nevertheless emerge.

Drawing as a coherent graphic language and the representation of architecture as a tool for analysis and a means of visual communication were developed on the basis of the use of documentary sources, thus integrating the graphic-representative experience with the essential skill of being able to research, analyse the sources, integrate them and propose syntheses. This work provided, on the one hand, the basis for three-dimensional modelling and the elaboration of two-dimensional representations, and on the other hand, the development of interpretative graphic syntheses in which the proposed communication strategies revealed interesting knowledge paths and equally interesting graphic elaborations of the architectures analysed. 


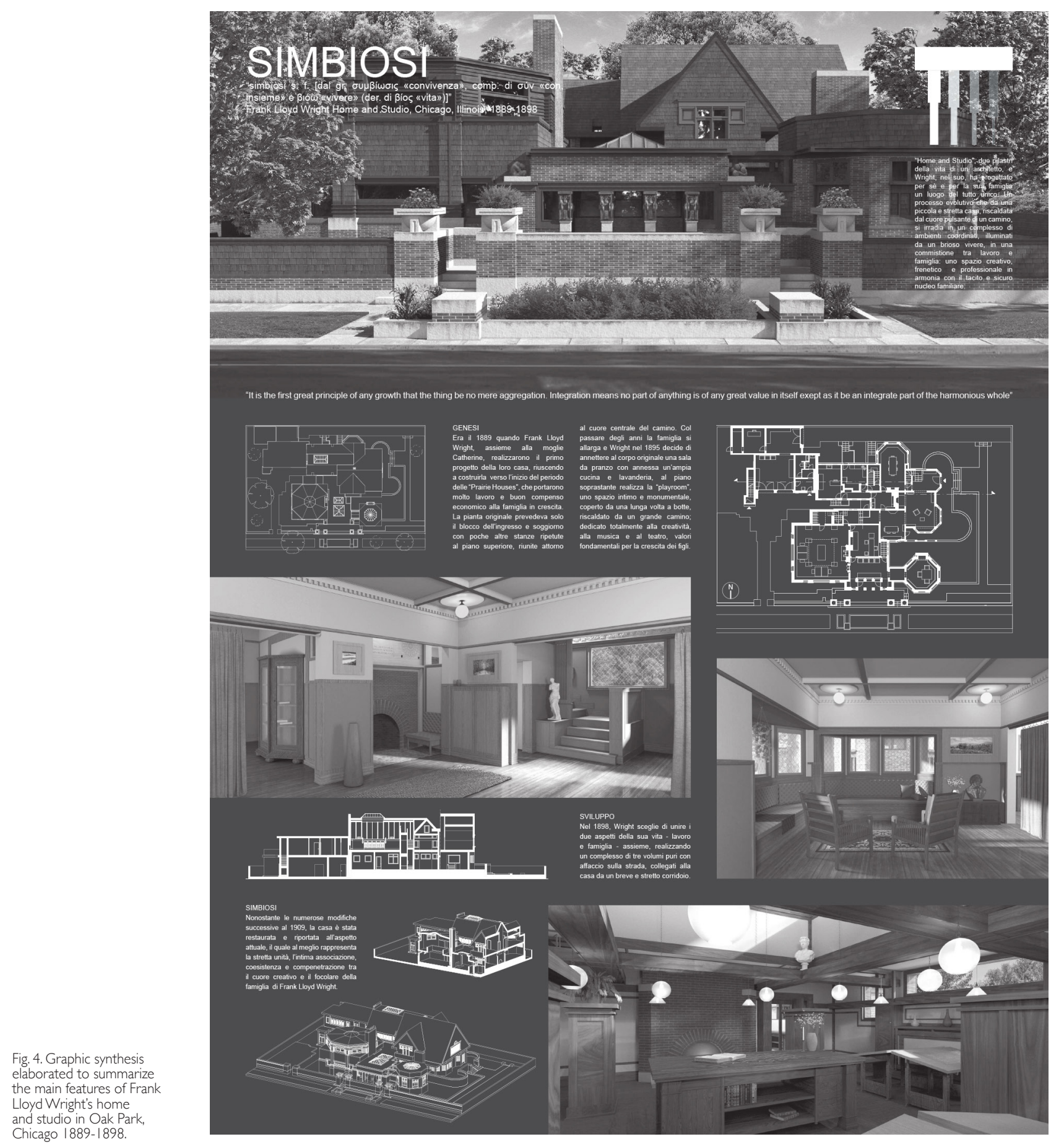




\section{Note}

[I] The research on Modernist architecture in India and Latin America, from which the in-depth study of architecture in the United States derives, was developed by the DIAPReM centre of the Department of Architecture at the University of Ferrara, under the scientific coordination of the centre's Head, Professor Marcello Balzani, also as part of doctoral courses, international workshops and teaching experiences. The results described in this paper are part of the activities carried out in the framework of the integrated course of Survey II and Techniques of Representation, Department of Architecture, University of Ferrara, AA 2020-2021, professors Federica Maietti and Andrea Zattini.

\section{References}

Albisinni P., Chiavoni E. (a cura di). (2014). Sul disegno dell'architettura: esperienze e riflessioni. Roma: Aracne.

Benevolo L. (20I0). Storia dell'architettura moderna. Bari: Laterza.

Bertocci S., Bini M. (20I2). Manuale di rilievo architettonico e urbano. Novara: CittàStudi Edizioni.

Bianchini C. (20 I4). Survey, modeling, interpretation as multidisciplinary components of a Knowledge System. In SCIRES-IT-SCIentific RESearch and Information Technology. n. 4.I, pp. I5-24.

Brusaporci S. (ed.). (2019). Handbook of research on emerging digital tools for architectural surveying, modeling, and representation. Hershey, PA: IGI Global.

Clini P., Quattrini R. (2020). Umanesimo Digitale e Bene Comune? Linee guida e riflessioni per una salvezza possibile/Digital humanities and Commons: guidelines and recflections for a possible salvation. In II Capitale Culturale. Studies on the Value of Cultural Heritage. n. I I, pp. $157-175$.

De Luca L. (20I I). La fotomodellazione architettonica: rilievo, modellazione, rappresentazione di edifici a partire da fotografie. Palermo: Dario Flaccovio Editore.

Docci M., Filippa M., Chiavoni, E. (20I I ). Metodologie integrate per il rilievo, il disegno, la modellazione dell'architettura e della città. Roma: Gangemi Editore.

Fatta F. (2020). Prefazione. In Arena A. et al. (a cura di). Connettere. Un disegno per annodare e tessere. Atti del $42^{\circ}$ Convegno Internazionale dei Docenti delle Discipline della Rappresentazione. Milano: FrancoAngeli, pp. I3-24.

Frampton K. (1993). Storia dell'architettura moderna. Bologna: Zanichelli Editore.

Lo Turco M., Giovannini E. C. (2020). Towards a physical heritage approach for museum collection. In Journal of Archaeological Science: Reports, n. 34, 102639.

Luigini A. et al. (eds.). (2017). Proceedings of International and Interdisciplinary Conference IMMAGINI? Image and Imagination between Representation, Communication, Education and Psychology, vol. I, Issue 9.

Rossato L. (2020). When Brazil and India were modernist. Processes of digital documentation for the preservation of 20th century architectures. Rimini: Maggioli Editore.

Zevi B. (2004). Storia dell'architettura moderna. Milano: Einaudi.

\section{Authors}

Federica Maietti, University of Ferrara, federica.maietti@unife.it

Andrea Zattini, University of Ferrara, andrea.zattini@unife.it

To cite this chapter: Maietti Federica, Zattini Andrea (2021). Between survey and communication. On distance experiences. In Arena A., Arena M. Mediati D., Raffa P. (a cura di). Connettere. Un disegno per annodare e tessere. Linguaggi Distanze Tecnologie. Atti del $42^{\circ}$ Convegno Internazionale de Docenti delle Discipline della Rappresentazione/Connecting. Drawing for weaving relationship. Languages Distances Technologies. Proceedings of the $42^{\text {th }}$ International Conference of Representation Disciplines Teachers. Milano: FrancoAngeli, pp. $1725-1733$. 